\title{
Dose Rate Calculation and Shields Estimation for the Reactor Vessel Model Simulation Concept using MicroShield Code at the VVR-S Nuclear Research Reactor, Bucharest Magurele
}

\author{
I. IORGA ${ }^{a, b, *}$
}

${ }^{a}$ Horia Hulubei National Institute of Physics and Nuclear Engineering (IFIN-HH), P.O. Box MG-6, RO-077125, Magurele, Romania

${ }^{b}$ Faculty of Physics, University of Bucharest, P.O. Box MG-11, 077125, Bucharest-Magurele, Romania

The VVR-S Nuclear Research Reactor owned by Horia Hulubei National Institute for Physics and Nuclear Engineering (IFIN-HH), was built in Romania between 1955 and 1957. The research reactor operated until 1997 and was permanently shut-down in 2002. During his life-time, it was functional for $113467 \mathrm{~h}$, including $2000 \mathrm{~h}$ at $3.0 \mathrm{MW}$ power. It had a utilization factor of $65 \%$ with an average of $1 \mathrm{MW}$ thermal power. VVR-S means that is a thermal neutrons reactor model S moderated cooled and reflected with distilled water, fueled with enriched uranium $10 \%$ in the beginning and $36 \%$ subsequently. Maximum values of dose rate at external aluminum vessel wall were between $3.5 \mathrm{mSv} / \mathrm{h}$. and $9 \mathrm{mSv} / \mathrm{h}$. Maximum values of the inner aluminum vessel near the active core were between $7.85 \mathrm{mSv} / \mathrm{h}$. and $16.62 \mathrm{mSv} / \mathrm{h}$ in accordance with the location the experimental channels. Problematic dose rate appeared on the vessels parts that included reactor core with maximum value that was $140 \mathrm{mSv} / \mathrm{h}$ at $10 \mathrm{~cm}$, near thermal column inside the aluminum vessel. Other internal values vary between $400 \mu \mathrm{Sv} / \mathrm{h}$ and $35 \mathrm{mSv} / \mathrm{h}$ at $10 \mathrm{~cm}$ from the wall. The principal radionuclides implicated were: ${ }^{60} \mathrm{Co},{ }^{137} \mathrm{Cs},{ }^{152} \mathrm{Eu}$ and ${ }^{154} \mathrm{Eu}$ with theirs correlation factors respectively for $\left({ }^{90} \mathrm{Sr}-{ }^{90} \mathrm{Y}\right)$ for beta active radionuclide evaluation. We needed to respect the radiation protection program dose limit of $20 \mathrm{mSv} /$ year for the personnel professionally exposed. For this reason the simulation of the potential dose rate exposure and the shield calculation was necessary.

DOI: 10.12693/APhysPolA.135.1087

PACS/topics: modelling, methodology simulation, dose rate assessment, exposure rate

\section{Introduction}

The VVR-S Nuclear Research Reactor owned by Horia Hulubei - National Institute for Physics and Nuclear Engineering (IFIN-HH), was built in Romania between: 1955-1957. The research reactor operated until 1997 and was permanently shut-down in 2002. During his life time, it was functional for a period of $113467 \mathrm{~h}$, including $2000 \mathrm{~h}$ at 3.0-3.5 MW power. The research reactor operated until 1997 and was permanently shut-down in 2002. The total power output up to 1997 was $9.59 \mathrm{GWd}$. It had a utilization factor of $65 \%$ (approximate 9510 effective days of operation) with an average of $1 \mathrm{MW}$ thermal power. It was the first research reactor using the VVR-S type soviet design. The main role of the reactor was for research and radioisotope production. VVR-S means that is a thermal neutrons reactor model S moderately cooled and reflected with distilled water, fueled with enriched uranium $10 \%$ in the beginning and $36 \%$ subsequently [1-2]. Nuclear reactor active core has been designed to provide a nominal power of $2000 \mathrm{~kW}$, of a maximum and medium thermal neutrons flux of $2 \times 10^{13}$ and $10^{13} \mathrm{n} / \mathrm{cm}^{2} \mathrm{~s}$ respectively and it is a variant of the experimental reactor realized in the USSR with a higher power [2].

*e-mail: johnny@nipne.ro

\section{System description}

Biological protection of the block reactor consists from the wall of the aluminum inner vessel, water layer between the inner cup and the middle wall of the aluminum vessel, the wall of the aluminum middle vessel, water

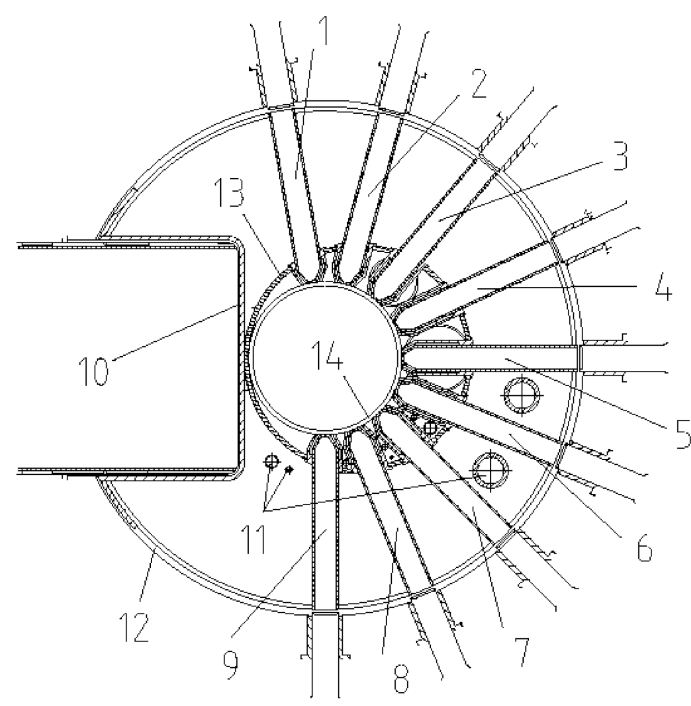

Fig. 1. $70 \mathrm{~cm}$ high part of aluminum vessel embeding the reactor core: $1-9-$ horizontal channels, $10-$ aluminum wall were the thermal column began, 11 - vertical channels, 12 - external vessel, 13 - internal vessel, 14 - internal vessel containing the separator [2]. 
layer between middle vessel and the outer wall aluminum vessel, outer lining (shield) cast iron and a wall of heavy concrete, with added iron ore and limestone, with density $3.2 \mathrm{~kg} / \mathrm{dm}^{3}$ and $226 \mathrm{~cm}$ thick. Concrete protection shield was crossed horizontally by the channel of the thermal column and 9 experimental channels and complex set of vertical pits: 3 channels for biological experiments; 4 channels for monitoring; the channel for stabilizing the stem unloading mechanism for the active area; 7 channels and ionization chambers providing data for adjusting the control rods and protection system; 7 storage channel containing ionization chambers corks, control rods and protection system; 2 experimental channels for thermal column and 2 channels for keeping the corks of these two experimental spinal thermal channels; 2 channels keeping vertical channels corks of the thermal column located in the reactor vessel. Side protection was also crossed by the inclined channel for transport of the irradiated fuel deposit boxes for cooling, consisting of two concentric tubes: the outer nade of steel and the inner made of aluminum and two vertical channels that linked the slanted transport channel to the hot cell no. 1 . In protecting concrete are practiced ventilation channels to the upper part of the reactor and lighting system channel for controlling the reactor core [1-2].

VVR-S Nuclear Research Reactor aluminum vessels were: external vessel with $2245 \mathrm{~mm}$ internal diameter, 20-16 mm wall thickness, and $5700 \mathrm{~mm}$ vessel height; internal vessel with $1100 \mathrm{~mm}$ internal diameter, 14-12 mm wall thickness, and $5700 \mathrm{~mm}$ height; central vessel with $670 \mathrm{~mm}$ internal diameter, $12 \mathrm{~mm}$ wall thickness, and $1825 \mathrm{~mm}$ height and in the end the separator vessel with $645 \mathrm{~mm}$ internal diameter, 8-6 $\mathrm{mm}$ wall thickness, $850 \mathrm{~mm}$ height and weight of $52 \mathrm{~kg}$. The total aluminum weight of vessels was $3640 \mathrm{~kg}$ [1-2]. Various dismantling steps of the reactor aluminum vessels were carried out in 2016. Our main scope was to calculate and simulate the effective dose exposure. MicroShield ${ }^{\circledR} 9.04$ tool code was used. This system is oriented toward radioprotection issuer and shields calculation. In decommissioning process the reactor vessels were split horizontally into seven parts. Very heavy parts were turned onto smaller chunks to make handling the pieces easier and safer from technical and radiological points of view. First of all we had focused our interest on the aluminum vessels parts because of its level of radiation was particularly high, especially in the $70 \mathrm{~cm}$ height slice surrounding the reactor core. This part is shown in Fig. 1.

\section{Results and discussion}

We had considered that the dismantling will be done remotely so the worker will spend a limited time exposed at the $80 \mathrm{~cm}$ distance from vessel. We had simulated the partition of the vessels onto 12 horizontal layers based on the dosimetry measurements at $10 \mathrm{~cm}$ distance to the vessels walls. On the basis of spectrometric data measurement and calculations we theoretically calculation we found the quantity and activity of the radionuclides involved. The principal isotopes were: ${ }^{60} \mathrm{Co}$, ${ }^{137} \mathrm{Cs},{ }^{152} \mathrm{Eu}$ and ${ }^{154} \mathrm{Eu}$ with their correlation factors, respectively ${ }^{90} \mathrm{Sr}-{ }^{90} \mathrm{Y}$ for beta emitting radionuclide evaluation. For simulation purpose we use geometry permutation and commutative proprieties to restore the reality on the MicroShield program. Because of asymmetry of the aluminum vessel arrangements we needed to implement special integration methods including many elements of symmetry, taking into account absorption factors and geometry.

Maximal dose rates at external aluminum vessel wall were between $3.5 \mathrm{mSv} / \mathrm{h}$ and $9 \mathrm{mSv} / \mathrm{h}$, and at the inner aluminum vessel close to the core - between $7.85 \mathrm{mSv} / \mathrm{h}$ and $16.62 \mathrm{mSv} / \mathrm{h}$ in the vinicity of the experimental channels. So, specific measures were taken by building thick protective shields suitable for dose reduction. We use lead with 1 to $2 \mathrm{~cm}$ thick.

For the determination of simulation accuracy we used the probe sample measurements on the specific points. The results were compared with the simulated, expected values. The data fits with the accuracy between $71.43 \%$ and $77.78 \%$, despite the complex shapes and the asymmetry of the aluminum reactor vessels.

The problematical dose rate appeared only on the closest vessel part to the reactor core - maximum value at $10 \mathrm{~cm}$ distance to the thermal column location was $140 \mathrm{mSv} / \mathrm{h}$. Other internal values vary between $400 \mu \mathrm{Sv} / \mathrm{h}$ and $35 \mathrm{mSv} / \mathrm{h}$ at $10 \mathrm{~cm}$ from the wall.

\section{Conclusion}

The pieces of cutted aluminum vessels are in interim storage in former spent fuel storage facility. The dismantling of the reactor vessels at the VVR-S Nuclear Research Reactor was performed without incidents. All activities were monitored from the point of view of health and safety, radioprotection, environmental protection and so on.

It is desirable to make the necessary considerations before performing a risky activity, thus simulating the possible doses that can be collected by the personnel, helps to respect the ALARA principle and help organize more effectively the decommissioning activities

\section{Acknowledgments}

The paper is a part of the research activities done within the Decommissioning Project of the IFIN-HH VVR-S Nuclear Research Reactor.

\section{References}

[1] M. Dragusin, V. Copaciu, V. Popa, C. Dragolici, I. Iorga, R. Deju, C. Mustata, C. Tuca, I. Mincu, Decommissioning Plan of the VVR-S Research Reactor, ROM 04 029/2003, applicable revision.

[2] VVR-S RFS Reactor - VVR-S - Reactor Final Security Report, ISPE Bucharest 1972. 